\title{
Analyze the Mechanical Characterization of Glass Fiber- Epoxy Modified Composite Materials
}

\author{
Sivakumar Chelliah \& Geetha Selvarani Arumaikkani
}

\begin{abstract}
The weight reduction with enhanced strength is the primary requirement of Automobile Engineering field. Fiber which serves as a reinforcement in reinforced plastics may be synthetic or natural past studies show that only artificial fibers such as glass, carbon etc., have been used in fiber reinforced plastics. Nowadays silencer covers are making from conventional materials like stainless steel. Disadvantages of using conventional materials are more weight and higher manufacturing cost. Instead of going for conventional material the present study is reduce the weight of the product and minimize the cost. The significant technical advance is to identify the new composite material, which consists of glass fiber/modified epoxy laminates with inclusion of nano fillers .This material will be used to fabricate new auto ancillary parts and its mechanical characteristics will be analyzed. Parts produced by these materials are obtained more strength and life time than the existing parts and which is helpful for human beings and environment.
\end{abstract}

Keywords-Glass Fiber, Epoxy, Composite Material

\section{Introduction}

Necessity is the mother of invention. Our needs are increasing day-by-day. Hence it is necessary to develop more and more new things. This includes invention of new modern materials for comfort. Also, a traditional material needs to be replaced for satisfying our requirements in some specific applications like aerospace, dentistry, automobile, construction etc. Hence we started using the materials manufactured by proper blending of two or more materials. That resulting material is so called as Composite Material.

A composite is combination of two materials in which one of the materials, called the reinforcing phase, is in the form of fibers, sheets, or particles, and is embedded in the other materials called the matrix phase. The reinforcing material and the matrix material can be metal, ceramic, or polymer. Composites typically have a fiber or particle phase that is stiffer and stronger than the continuous matrix phase and serve as the principal load carrying members. The matrix acts as a load transfer medium between fibers, and in less ideal cases where the loads are complex, the matrix may even have to bear loads transverse to the fiber axis. The matrix is more ductile than the fibers and thus acts as a source of composite toughness. The matrix also serves to

\section{SIVAKUMAR CHELLIAH}

Assistant Professor,

Department of Mechanical Engineering,

GEETHA SELVARANI ARUMAIKKANI 2

Professor, Department of Civil Engineering,

Vel Tech Rangarajan DR.Sangunthala R\& D Institute of Science and

Technology,

Avadi, Chennai, Tamil Nadu, India protect the fibers from environmental damage before, during and after composite processing. When designed properly, the new combined material exhibits better strength than would each individual material. Composites are used not only for their structural properties, but also for electrical, thermal, tribological, and environmental applications.: High strength to weight ratio (low density high tensile strength) ,High creep resistance, High tensile strength at elevated temperatures, High toughness. Common fiber reinforced composites are composed of fibers and a matrix. Fibers are the reinforcement and the main source of strength while matrix glues all the fibers together in shape and transfers stresses between the reinforcing fibers. Sometimes, filler might be added to smooth the manufacturing process, impact special properties to the composites, and / or reduce the product cost. Particles used for reinforcing include ceramics and glasses such as small mineral particles, metal particles such as aluminium and amorphous materials, including polymers and carbon black. Particles are used to increase the modules of the matrix and to decrease the ductility of the matrix

\section{A.Glass Fiber}

The most common types of glass fiber used in fiberglass is E-glass, which is alumino-borosilicate glass with less than $1 \% \mathrm{w} / \mathrm{w}$ alkali oxides, mainly used for glass-reinforced plastics. Other types of glass used are A-glass (Alkali-lime glass with little or no boron oxide), E-CR-glass (Electrical/Chemical Resistance; alumino-lime silicate with less than $1 \% \mathrm{w} / \mathrm{w}$ alkali oxides, with high acid resistance), C-glass (alkali-lime glass with high boron oxide content, used for glass staple fibers and insulation), D-glass (borosilicate glass, named for its low Dielectric constant), Chopped strands ranging in Length from 3.2to12.7mm.



Fig.1 Glass Fiber 
Proc. of the Eighth International Conference On Advances in Applied Science and Environmental Engineering - ASEE 2018 Copyright (C) Institute of Research Engineers and Doctors. All rights reserved.

ISBN: 978-1-63248-143-6 doi: 10.15224/ 978-1-63248-143-6-03

\section{B. EPOXY}

Epoxy resin is defined as a molecule containing more than one epoxide groups, epoxide groups also termed as oxirane or ethoxyline group. There are two types of DGEBA available



Fig 2 Diglycidyl ether Bisphenol A Resin (DGEBA)

A common starting material is DGEBA (diglycidyl ether Bisphenol A ), which contain two epoxide groups one at each end of molecule (Fig.2).Epoxy offer ease of processing excellent fracture toughness, good fiber impregnation properties and more durable, more solvent resistant and have a higher maximum operating temperature and its properties shown in Table 1.

Table : 1 DGEBA PROPERTIES

\begin{tabular}{|c|l|c|}
\hline 1 & Density & 1.2 to $1.3 \mathrm{~g} / \mathrm{cm} 3$ \\
\hline 2 & \multirow{2}{*}{ Tensile strength } & $55-130 \mathrm{Mpa}$ \\
\cline { 3 - 3 } & & $8000-9000 \mathrm{psi}$ \\
\hline 3 & Tensile Modulus & $2.75-4.10 \mathrm{Gpa}$ \\
\hline 4 & Poisson's ratio & 0.2 to 0.33 \\
\hline 5 & Shrinkage percentage & 1 to 5 \\
\hline
\end{tabular}

\section{NANO FILLER}

The recent introduction of nanoclay as fillers or additives in polymers for various desired effects is a subject of an increased interest for research and development to establish various applications. Nanoparticles used as fillers or additives in polymers for various desired effects are receiving an increased interest for research and development. Various types of nanoparticles, including nanocarbon, carbon nanotubes, nanoclay, and metal oxides, are currently used to modify the polymer performance. Montmorillonite is a very soft phyllosilicate mineral that typically forms in microscopic crystals, forming clay. It is named after Montmorillonite in France. Montmorillonite, a member of the Smectite family, is 2:1 clay, meaning that it has 2 tetrahedral sheets sandwiching a central octahedral sheet. The particles are plate-shaped with an average diameter of approximately 1 micrometre. It is the main constituent of the volcanic ash weathering product, Bentonite.



Fig 3 Structure of Nano Clay

\section{Methodology}

Composite materials have rapidly become a material of choice as an alternative to other traditional materials such as metals and have found applications in many sectors. Thermosetting resins are widely used with glass fibres for automotive and building application .It is necessary to characterize the effect of mechanical properties like Ductility, Brittleness, fatigue, stiffness-to-weight ratio make the composite materials with unique mechanical properties in the design and manufacturing of various components. So it is decided to carry out research if the above topic and analyse the following mechanical properties like.

$$
\begin{array}{ll}
> & \text { Tensile Test } \\
> & \text { Flexural Test } \\
> & \text { Impact Test }
\end{array}
$$

\section{A.MATERIALS USED:}

FIBER+ (EPOXY RESIN+HARDNER) + NANO Filler

$>$ Fiber: E-Glass Fiber

$>$ Epoxy Resin: Dgeba (Diglycidyl Ether Bisphenol A) Based Araldite Ly 556

$>$ Hardener - Araldite Hy 951

$>$ Acetone - Laboratory Grade

$>$ Nano Filler: Montmorillonite Nano clay ( I 30P )

\section{B. EPOXY MODIFICATION PROCESS:}

Detailed description shown in table 2 and 3.

Epoxy + Hardener $=>100: 10$

Nano clay:

Table 2 Loading \% of Nano Clay

\begin{tabular}{|c|c|c|c|c|c|c|}
\hline S.NO & Grade & \multicolumn{5}{|c|}{ Loading (\%) } \\
\hline 1 & I 30P & 2 & 4 & 6 & 8 & 10 \\
\hline
\end{tabular}


Proc. of the Eighth International Conference On Advances in Applied Science and Environmental Engineering - ASEE 2018 Copyright (c) Institute of Research Engineers and Doctors. All rights reserved.

ISBN: 978-1-63248-143-6 doi: 10.15224/ 978-1-63248-143-6-03

Table 3 MIXTURE CALCULATION

\begin{tabular}{|r|c|c|c|c|c|}
\hline \multirow{2}{*}{ S.NO } & \multicolumn{2}{|c|}{$\begin{array}{c}\text { NANO } \\
\text { CLAY }\end{array}$} & \multirow{2}{*}{ EPOXY } & HARDENER & TOTAL \\
\cline { 2 - 4 } & $\%$ & Gms & & & \\
\hline 1 & 2 & 4 & 176.4 & 19.6 & 200 \\
\hline 2 & 4 & 8 & 172.8 & 19.2 & 200 \\
\hline 3 & 6 & 12 & 169.2 & 18.8 & 200 \\
\hline 4 & 8 & 16 & 165.6 & 18.4 & 200 \\
\hline 5 & 10 & 20 & 162 & 18 & 200 \\
\hline
\end{tabular}

\section{EXPERIMENTAL DETAILS:}

Initially nanoclay was dissolved in solvent acetone and stirred well by using glass rod. The resin and hardener is taken in the ratio of 100:10 parts by weight respectively. Nanoclay was mixed with Epoxy resin based on the previously discussed mixer calculation. Then by using mechanical stirrer the Nanoclay/Epoxy mixure was thoroughly mixed together for $30 \mathrm{~min}$. Furthermore, the mixure was again mixed by ultra sonicator for $30 \mathrm{~min}$. The pre-calculated amount of hardener is mixed with Epoxy mixture and then stirred well by using glass rod. Finally, the mixture was poured into mould and allowed to cure for $24 \mathrm{~h}$ at room temperature.

\section{MECHANICAL TESTING:}

The prominent mechanical tests like tensile, flexural and impact were done on the laminates prepared using glass fiber reinforced polymer with modified epoxy.

\section{Tensile test:}

This laminate is cut to standard sizes to make specimens for mechanical testing. For tensile test as per ASTM standard D638 samples are cut to $(250 \times 25 \times 3) \mathrm{mm}$. The tensile test is carried out in a computerized UTM machine. The specimens are clamped at both the ends by the fixed head than tensile load is applied at both the ends the displacement is converted into values by means of load cell. The arrangement for tensile testing is depicted in fig 4 ..



Fig 4Tensile testing arrangement

\section{Flexural test:}

For flexural test as per ASTM standard D790 samples are cut to $(127 \times 13 \times 3) \mathrm{mm}$. The flexural test is carried out in a computerized UTM machine. Flexural test is used to check the bending strength of the specimen. The testing is done in 3point mode in which the specimen is supported at both ends and load is applied at middle section vertically downwards. The displacement is converted in to values by means of load cell. The arrangement for flexural testing is depicted in fig 5 .



Fig. 5 Flexural testing arrangement

\section{Impact test:}

For flexural test as per ASTM standard D256 samples are cut to $(127 \times 13 \times 3) \mathrm{mm}$. Impact testing measures the amount of energy lost during the pendulum strikes the work piece. The arrangement for impact testing is depicted in fig 6.



Fig.6 Impact testing arrangement

\section{Result and Discussion}

This chapter presents the mechanical properties of the glass fiber reinforced polymer with modified epoxy composites prepared for this present investigation.The results of various characterization tests are reported here. These includes evaluation of tensile strength, flexural strength, impact strength has been studied and discussed.

Table 4 TEST RESULTS

\begin{tabular}{|c|c|c|c|c|c|c|}
\hline \multirow{2}{*}{\multicolumn{2}{|c|}{$\begin{array}{l}\text { Composite } \\
\text { Laminates } \\
\text { Details }\end{array}$}} & \multicolumn{2}{|c|}{ Tensile Test Results } & \multicolumn{2}{|c|}{$\begin{array}{ll}\text { Flexural } & \text { Test } \\
\text { Results } & \end{array}$} & \multirow{2}{*}{$\begin{array}{l}\text { Impact } \\
\text { Test } \\
\text { Results } \\
(\mathrm{J})\end{array}$} \\
\hline & & \multirow{2}{*}{$\begin{array}{l}\text { Peak } \\
\text { Load [N] } \\
1174.25\end{array}$} & \multirow{2}{*}{$\begin{array}{l}\text { Ultimate } \\
\text { Tensile } \\
\text { Strength } \\
{\left[\mathrm{N} / \mathrm{mm}^{2}\right]} \\
16768\end{array}$} & \multirow{2}{*}{$\begin{array}{l}\begin{array}{l}\text { Peak } \\
\text { Load } \\
{[\mathrm{N}]}\end{array} \\
54.95\end{array}$} & \multirow{2}{*}{$\begin{array}{l}\text { Flexural } \\
\text { Strength } \\
\text { [MPa] } \\
38.75\end{array}$} & \\
\hline \multirow{5}{*}{$\begin{array}{c}\text { without } \\
\text { fiber }\end{array}$} & $2 \%$ & & & & & 0.3 \\
\hline & $4 \%$ & 1133.66 & 15.11475 & 47.28 & 33.34 & 0.42 \\
\hline & $6 \%$ & 521.82 & 10.325 & 32.81 & 23.14 & 0.21 \\
\hline & $8 \%$ & 763.14 & 9.189 & 38.35 & 27.05 & 0.23 \\
\hline & $10 \%$ & 441.49 & 6.958 & 31.64 & 22.31 & 0.23 \\
\hline \multirow{5}{*}{$\begin{array}{l}\text { With } \\
\text { Fiber }\end{array}$} & $2 \%$ & 12931.77 & 170.453 & 231.44 & 164.19 & 2.77 \\
\hline & $4 \%$ & 12140.74 & 162.587 & 225.20 & 164.79 & 2.15 \\
\hline & $6 \%$ & 10925.26 & 4.65666 & 228.49 & 147.23 & 2.36 \\
\hline & $8 \%$ & 10832.10 & 4.91777 & 208.79 & 162.46 & 2.4 \\
\hline & $10 \%$ & 10702.91 & 4.92444 & 199.86 & 140.93 & 2.25 \\
\hline
\end{tabular}


Proc. of the Eighth International Conference On Advances in Applied Science and Environmental Engineering - ASEE 2018 Copyright (C) Institute of Research Engineers and Doctors. All rights reserved.

ISBN: 978-1-63248-143-6 doi: 10.15224/ 978-1-63248-143-6-03

\section{A.TENSILE TEST}

Tensile testing of specimen prepared according to ASTM D 3039 type IV sample was carried out, using electronic tensile testing machine with cross head speed of 5 $\mathrm{mm} / \mathrm{min}$ and a gauge length of $50 \mathrm{~mm}$.



Fig.7 Peak Load vs. \% of Nano Clay



Fig 8. Ultimate Strength vs. \% of Nano clay

The tensile modulus and elongation at the break of the composites were calculated from the stress strain curve. Four specimens were tested for each set of samples and the mean values were reported. The maximum of ultimate strength value for fiber ratio. The first graph fig.7 and fig 8 Shows $2 \%$ of Nano Clay has good results when compared with the other with and without fiber samples. To improved chemical bonding and helped to withstand high tensile load by the composites made of them. To compare other ratio the first sample gave better tensile strength. It is observed that ultimate tensile strength is maximum for $2 \%$ of Nano clay for both with and without fiber.

\section{B. FLEXURAL TEST}

The flexural test was performed by the three points bending method according to ASTM D 790-03, and cross head speed of $1 \mathrm{~mm} / \mathrm{min}$. Four specimens were tested, and the average was calculated. The specimen was freely supported by a beam, the maximum load was applied in the middle of the specimen, and the flexural modulus is calculated from the slope of the initial portion of the load deflection curve. The first graph fig. 9 and fig 10 . Shows $2 \%$ of Nano Clay has good results when compared with the other with and without fiber samples. To improved chemical bonding and helped to withstand high tensile load by the composites made of them. To compare other ratio the first sample gave better tensile strength. It is observed that ultimate flexural strength is maximum for $2 \%$ of Nano clay for both with and without fiber.



Fig. 9Peak Load vs. \% of Nano Clay

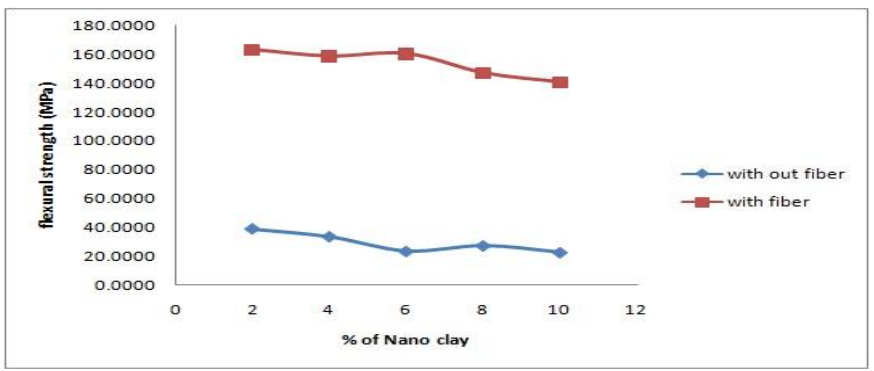

Fig. 10 Flexural Strength vs. \% of Nano Clay

\section{IMPACT TEST:}

Impact is a single point test that measures a materials resistance to impact from a swinging pendulum. Impact is defined as the kinetic energy needed to initiate fracture and continue the fracture until the specimen is broken. This test can be used as a quick and easy quality control check to determine if a material meets specific impact properties or to compare materials for general toughness. The fig.11. Shows $2 \%$ of Nano Clay has good results when compared with the other with and without fiber samples. It is observed that $2 \%$ of nano clay yield highest impact resistance for the given load.

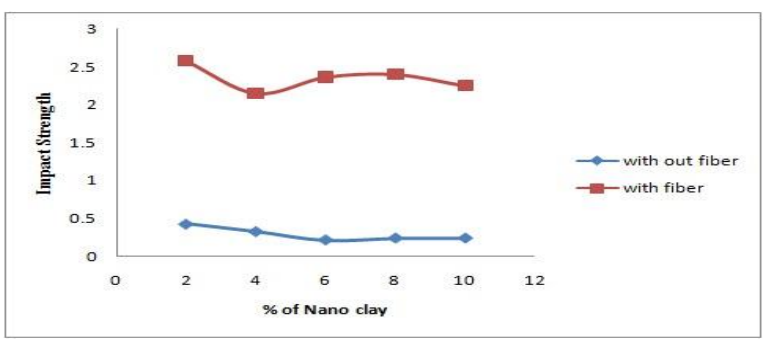

Fig. 11 Impact Strength vs. \% of Nano Clay

\section{Iv.Conclusion}

The effect of nanoclay presence into epoxy based fiber glass composites was investigated. By applying direct mixing with the usage of a dispersant agent, acetone, it was possible to prepare a laminate nanocomposite with nano modified epoxy resin. The void content reduction seems to be the result of chemical reactions between the nanoclay, hardener, acetone and the resin itself. During the nano modified matrix formation, the mixture temperature was constantly monitored. The test results clearly depicted the $2 \%$ loading of nano clay is best among all other percentage of nano clay. Hence silencer cover will be fabricated by using $2 \%$ of nano clay. 


\section{References}

[1] Antonio F. Avila, Marcelo I. Soares, Almir Silva NetO, (2007) "A study on nanostructure laminated plates behavior under low-velocity impact loadings", Composites Science and Technology, Vol 71, pp $.1606-1611$.

[2] Yuan Xu, Hongbin Shen B, Maria L. Auad C, Changzheng Huang A, Steven Nutt A, (2008) "Mechanical properties of carbon fiber reinforced epoxy/clay nanocomposites", Composites: Part A, Vol. 40 ,pp.1082-1089.

[3] Antonio F, A Vila, Whelan, (2009), "Modeling nanoclay effects into laminates failure strength and porosity", Composites: Part B Vol.42, .pp .105-116.

[4] Veronica Morote, Toshiya Kamae, Lawrence T. Drzal, (2011), "Addition of unmodified nanoclay to improve the performance of unsaturated polyester resin coating on natural stone", Composites: Part A, Vol. 43, pp.1569-1577.

[5] Vero nica Morote, Alexander Bismarck B, Emile S. Greenhalgh C, Milo S.P. Shaffer A, (2011) "Addition of unmodified nanoclay to improve the performance of unsaturated polyester resin coating on natural stone", Composites: Part A, Vol.41, pp.1107-1114.

[6] Hui Qian A, B, Alexander Bismarck B, Emile S. Greenhalgh C, Milo S.P. Shaffer A, (2010) "Fabrication and mechanical characterization of carbon/Sic-epoxy nanocomposites", Composites Science and Technology, Vol. 70, pp.393-399.

[7] Kevin L. White A, B, Hung-Jue Sue A, B, (2012) "Delamination toughness of fiber reinforced composites containing a carbon nanotube/polyamide-12 epoxy thin film interlayer", Polymer, Vol. 53, pp.37- 42 .

About Author (s):

C.SIVAKUMAR has completed his Post Graduate Degree in Engineering Design specialization and published paper in International and National reputed Journals and conferences and filed 3 patents. He presented a paper in $5^{\text {th }}$ International Conference on Civil Engineering and Urban Planning (CEUP2016) held in Xian, China from 23rd to 26th,August and also in international conference held on march 2017 at DUBAI. 